\title{
Interaction of Neuropeptide Y and Hsp90 through a Novel Peptide Binding Region ${ }^{\dagger}$
}

\author{
Haruko Ishiwatari-Hayasaka, ${ }^{*, \ldots, \S}$ Mikako Maruya, ${ }^{\ddagger}, 8$ Amere Subbarao Sreedhar, ${ }^{\|, \perp}$ Takayuki K. Nemoto, ${ }^{\#}$ \\ Peter Csermely," and Ichiro Yahara $\$,, \Delta$ \\ Department of Cell Biology, The Tokyo Metropolitan Institute of Medical Science, Tokyo 113-8613, Japan, \\ CREST, Japan Science and Technology Corporation, Saitama 332-0012, Japan, \\ Department of Biochemistry, Nagasaki University School of Dentistry, Nagasaki 852-8588, Japan, \\ Department of Medical Chemistry, Semmelweis University, H-1444 Budapest, Hungary, and \\ Ina Institute, Medical and Biological Laboratory, Co., Ltd., 1063-103, Ohara, Terasawaoka, Ina-City 396-0002, Japan
}

Received April 30, 2003; Revised Manuscript Received September 5, 2003

\begin{abstract}
Hsp90 is a molecular chaperone that binds and assists refolding of non-native and/or labile polypeptides and also bind various peptides. However, the rules of how Hsp90 recognizes substrates have not been well characterized. By surface plasmon resonance measurements, a physiologically active peptide, neuropeptide Y (NPY), with a strong binding property to Hsp90 was identified from screening of 38 randomly selected peptide candidates. We showed that the carboxy-terminal fragment of NPY (NPY13-36), which forms an amphipathic $\alpha$-helix structure, preserved the strong binding to Hsp90. Immunoprecipitation and immunoblotting using HeLa cell extracts revealed that newly synthesized NPY precursors bound to Hsp90, suggesting that the in vitro binding experiments identified an interactive peptide in vivo. Proteolytic cleavage of the NPY13-36/Hsp90 complex, as well as binding site analysis using deletion mutants of Hsp90, revealed the NPY binding locus on Hsp90 $\alpha$ as the 192 amino acid region following the $\mathrm{N}$-terminal domain. By electron microscopic analysis using an anti-Hsp90 antibody against the sequence proximal to the highly charged region, we showed that the Hsp90 dimer bound to NPY13-36 at both ends. Mutation of arginine residues in NPY13-36 to alanine abrogated binding to Hsp90. Our studies indicate that the hinge region after the N-terminal domain of Hsp90 and the positive charges on NPY are important for this interaction.
\end{abstract}

Hsp90 is a major molecular chaperone that is ubiquitous and abundant in eukaryotes and is essential for cell survival $(1-3)$. Under normal conditions, Hsp90 is indirectly involved in signal transduction pathways by assisting the proper folding of polypeptides and maintaining active states of substrates, such as transcription factors and protein kinases (3). In vitro analyses showed that Hsp90 binds and protects partially denatured proteins from irreversible aggregation and helps to refold polypeptides (4-6).

The Hsp90 polypeptide consists of over 700 amino acid residues and is divided into three functional and structural domains $(7,8)$. The N-terminal 200 amino acid residues contribute to ATP binding (9), of which tertiary structures

\footnotetext{
This work was conducted as a CREST research project and was supported by research grants from the EU 6th Framework Program (FP6506850), ICGEB (CRP/HUN99-02), Hungarian Science Foundation (OTKA-T37357), and Hungarian Ministry of Social Welfare (ETT32/03). A.S.S. is a recipient of a National Overseas Fellowship of the State of India.

* To whom correspondence should be addressed at the Department of Microbiology, University of Virginia, P.O. Box 441, Jordan Hall, 1300 Jefferson Park Ave., Charlottesville, VA 22908. Tel: 434-9245341. Fax: 434-982-0687. E-mail: hh9m@virginia.edu.

$\doteqdot$ The Tokyo Metropolitan Institute of Medical Science.

$\S$ CREST, Japan Science and Technology Corporation.

"Semmelweis University.

${ }^{\perp}$ On leave at Cellular and Molecular Biology, Hyderabad, 500007 India.

\# Nagasaki University School of Dentistry.

${ }^{\triangle}$ Ina Institute, Medical and Biological Laboratory, Co., Ltd.
}

have been determined by X-ray crystallography $(10,11)$. This domain has a chaperone activity to unfolded peptides in an ATP-dependent manner $(7,8)$. The N-terminal half of Hsp90 are shown to be located on the outer ends of the dimer by electron microscopic observations (12). The intermediate domain consists of a highly charged hinge region (amino acids 206-287) and the following domains similar to the MutL mismatch repair protein and DNA gyrase B (13). The highly charged region increases substrate affinity (14) and is required for chaperone activity (15), although this region is not present in HtpG, an Hsp90 homologue of Escherichia coli (16) and can be deleted without affecting growth in yeast (17). Recently, the middle domain is shown to contribute to cochaperone interaction and binding of client proteins (13, $18,19)$. The $\mathrm{C}$-terminal domain contributes to dimerization of Hsp90 $(20,21)$. Chaperone activity of Hsp90 has been located in this domain with different substrate specificity from the $\mathrm{N}$-terminus $(7,8,22)$. Although both the $\mathrm{N}$ - and the $\mathrm{C}$-terminal domains independently suppress aggregation of fully denatured polypeptides, the full length is required to refold partially denatured substrates (15).

The best-characterized natural substrates for Hsp90 are the steroid hormone receptors, whose activities are totally dependent on Hsp90 (23). Genetic and biochemical analyses using deletion mutants of steroid receptors showed that the hormone binding domains interact with Hsp90, whereas deletion mutants of Hsp90 did not reveal the involvement 
of a unique region in binding to steroid receptors $(24,25)$. Moreover, the binding sites for other substrates have been mapped on different regions of the Hsp90 polypeptide (26, 27). Hsp90 also recognizes various peptides as substrates $(7,8)$; however, a detailed characterization of the peptide binding specificity as well as regions of Hsp90 is lacking.

To examine the substrate binding characterization of Hsp90 in detail, we screened 38 biologically active peptides. We found that Hsp90 effectively interacts with neuropeptide $\mathrm{Y}$ (NPY), ${ }^{1}$ a positively charged amphipathic $\alpha$-helical polypeptide, through the region proximal to the $\mathrm{N}$-terminal domain of Hsp90. We proposed that an electrostatic interaction is involved in the intense binding between NPY and Hsp90.

\section{MATERIALS AND METHODS}

Purification of Hsp90. Hsp90 was purified from porcine brain as follows. Porcine brain (about $440 \mathrm{~g}$ ) was homogenized in buffer A (0.1 mM EDTA, $0.1 \mathrm{mM}$ PMSF, $20 \mathrm{mM}$ Tris-HCl, pH 7.5) containing $20 \mathrm{mM} \mathrm{NaCl}$. The homogenate was centrifuged at $22000 \mathrm{~g}$ for $10 \mathrm{~min}$ and then at $30000 \mathrm{~g}$ for $30 \mathrm{~min}$. The supernatant was mixed with DE-52 cellulose (Whatman International Ltd., Maidstone, U.K.) and stirred for $30 \mathrm{~min}$. Bound proteins were eluted with a linear gradient of $50-500 \mathrm{mM} \mathrm{NaCl}$ in buffer A. Fractions containing Hsp90 were pooled and dialyzed against $20 \mathrm{mM}$ potassium phosphate, $\mathrm{pH} 7.5$, and applied to a hydroxyapatite column (Bio-Rad, Richmond, CA). After the column was washed with $100 \mathrm{mM}$ potassium phosphate, proteins were eluted with a linear gradient of $100-300 \mathrm{mM}$ potassium phosphate, and fractions were pooled. The supernatant was $80 \%$ saturated with solid ammonium sulfate, and the mixture was centrifuged at $20000 \mathrm{~g}$ for $15 \mathrm{~min}$. Hsp90 precipitated by centrifugation was dissolved in an appropriate volume of a buffer (20 mM Tris- $\mathrm{HCl}, \mathrm{pH} 7.4,20 \mathrm{mM} \mathrm{NaCl}, 0.1 \mathrm{mM}$ EDTA) and was applied to a column of Q-Sepharose (Amersham Pharmacia Biotech, Ltd., Uppsala, Sweden) equilibrated with $50 \mathrm{mM}$ Tris- $\mathrm{HCl}(\mathrm{pH} 7.4)$ containing $10 \mathrm{mM} \mathrm{NaCl}$ and eluted with 10-1000 $\mathrm{mM} \mathrm{NaCl}$. Fractions containing Hsp90 were eluted through hydroxyapatite and then applied to Q-Sepharose again as described above. The final fractions containing Hsp90 were pooled, dialyzed against $20 \mathrm{mM}$ potassium phosphate, $\mathrm{pH} 7.4$, and stored at $-70{ }^{\circ} \mathrm{C}$. The purity of the $\mathrm{Hsp} 90$ protein was greater than $95 \%$ as judged by silver staining of SDS-polyacrylamide gels. Hsp90 preparations purified from the mouse lymphoma cell line, L5178Y, were provided by Dr. Y. Minami (Oita Medical University) and Dr. Y. Miyata (Kyoto University), respectively.

Preparation of Recombinant Hsp 90 . Fusion proteins with glutathione $S$-transferase (GST) were expressed in E. coli Y1090, and lysates were prepared as described (21). In brief, lysates $(1 \mathrm{~mL})$ were centrifuged at $12000 \mathrm{~g}$ for $10 \mathrm{~min}$ at 4 ${ }^{\circ} \mathrm{C}$ and adsorbed to glutathione-Sepharose 4B $(10 \mu \mathrm{L})$ equilibrated with PBS $(140 \mathrm{mM} \mathrm{NaCl}, 2.7 \mathrm{mM} \mathrm{KCl}, 10 \mathrm{mM}$ $\mathrm{Na}_{2} \mathrm{HPO}_{4}$, and $1.8 \mathrm{mM} \mathrm{K}_{2} \mathrm{HPO}_{4}, \mathrm{pH}$ 7.3). The matrix was

\footnotetext{
${ }^{1}$ Abbreviations: SPR, surface plasmon resonance; NPY, neuropeptide Y; PP, pancreatic polypeptide; PYY, peptide YY; GST, glutathione $S$-transferase; CD, circular dichroism; SA-HRP, streptavidin-horseradish peroxidase conjugate; RU, resonance units.
}

washed three times with $1 \mathrm{~mL}$ of PBS and collected by centrifugation at $500 \mathrm{~g}$ for $5 \mathrm{~min}$. Finally, the matrix was incubated with $10 \mu \mathrm{L}$ of 50 cleavage units $/ \mathrm{mL}$ thrombin in PBS for $2 \mathrm{~h}$ at room temperature to prepare recombinant proteins without a GST affinity tail. The purity of the samples was greater than $95 \%$ as judged by SDS-polyacrylamide gel electrophoresis.

Peptides, Proteins, and Monoclonal Antibodies. Peptides were purchased from the Peptide Institute Inc. (Osaka, Japan). Neuropeptide Y (NPY13-36), neuropeptide Y with arginine to alanine substitutions (NPY13-36-RA), NPY1336 with a cysteine residue at the carboxy terminus (NPY1336-Cys), NPY13-36-RA with cysteine (NPY13-36-RACys), pancreatic polypeptide (PP13-36), CK II heparin binding peptide (CLKPVKKKKIKREIKILENLR), the 21mer amino-terminal basic peptide of $\alpha$-casein (RPKHPIKHQGLPQEVLNENLL), and the 21-mer acidic peptide of $\alpha$-casein (EDQAMEDIKQMEAESISSSEE) were supplied by Iwaki Glass Co., Ltd. (Chiba, Japan). $\alpha$-Casein and histone $\mathrm{H} 1$ were purchased from Boehringer Mannheim and Sigma, respectively. Monoclonal antibodies against Hsp90 (K41116A, K41009, and K3720) were produced as described earlier (28). The monoclonal antibody against Hsp90 (3G3) and the monoclonal anti-Grp94 antibody (MA3-016) were purchased from Affinity Bioreagents Inc. The polyclonal NPY antibody (RB1) was supplied by Research Biochemicals International. Biotinylated anti-mouse IgG and biotinylated anti-rabbit $\operatorname{Ig}(\mathrm{G}+\mathrm{L})$ were purchased from Jackson ImmunoResearch Laboratories, Inc., and Vector Laboratories, respectively. A monoclonal anti-cellular fibronectin (FN-3E2; mouse $\operatorname{IgM}$ ) was purchased from Sigma.

Surface Plasmon Resonance (SPR) Spectrometry. Binding of various peptides to Hsp90 was determined by surface plasmon resonance (SPR) analysis using a BIAcore 1000 biosensor system (Biacore AB, Uppsala, Sweden) as described earlier $(26,29)$. All of the solutions for the SPR measurements were passed through a $0.22 \mu \mathrm{m}$ Millipore filter and degassed in a vacuum for $5 \mathrm{~min}$ at room temperature. Porcine Hsp90, L5178Y Hsp90, L5178Y Grp94, or recombinant Hsp90 was immobilized on the carboxymethylated dextran-coated sensor chips (Biacore $\mathrm{AB}$ ) at a concentration of $50 \mu \mathrm{g} / \mathrm{mL}$ in $10 \mathrm{mM}$ sodium acetate, $\mathrm{pH} 4.0$, using the amine coupling kit supplied by the manufacturer. Immobilization proceeded at $25{ }^{\circ} \mathrm{C}$ at a constant flow rate of 5 $\mu \mathrm{L} / \mathrm{min}$. Immobilization of Hsp90 yielded approximately 6800 or $8800 \mathrm{RU}$, corresponding to 6.8 or $8.8 \mathrm{ng}$ of $\mathrm{Hsp} 90 /$ $\mathrm{mm}^{2}$ sensor chip. Peptides $(25$ or $50 \mu \mathrm{M})$ in HBS buffer (10 $\mathrm{mM}$ HEPES, $\mathrm{pH} 7.4,150 \mathrm{mM} \mathrm{NaCl}$, and $3 \mathrm{mM}$ EDTA containing $0.005 \%$ P-20 surfactant) were injected to flow cells against the Hsp90-immobilized sensor chip at $25^{\circ} \mathrm{C}$ at flow rate of $5 \mu \mathrm{L} / \mathrm{min}$. For competition assay, NPY13-36 $(25 \mu \mathrm{M})$ and peptides or proteins were premixed at the indicated concentration and injected. The actual binding intensity of each sample was determined over a reference surface, where the matrix was blocked with amines. For binding of Hsp90 to NPY13-36, sensor chips were immobilized at the carboxy-terminal cysteine residue of either NPY13-36-Cys or NPY13-36-RA-Cys by 2-(2-pyridinyldithio)ethanolamine, and Hsp90 $(70-280 \mu \mathrm{g} / \mathrm{mL})$ was injected onto the peptide-coated sensor chip at flow rate of $10 \mu \mathrm{L} / \mathrm{min}$. Coupling was performed at $200 \mathrm{nM}$ peptide in $10 \mathrm{mM}$ sodium acetate, $\mathrm{pH} 4.0$, yielding approximately 830 
RU for NPY13-36-Cys and 1500 RU for NPY13-36-RACys. The reference surface was made by blocking the matrix with cysteine to correct for nonspecific binding to sensor chips. All of the binding experiments were repeated with "mock-coupled" sensor chips, where in the coupling procedure Hsp90 was omitted. Binding curves (sensorgrams) were corrected by subtracting the electrostatic binding of proteins and peptides used and the occasional changes in the refractive index after various additions. Special care was taken to reduce the latter phenomenon to the minimum throughout the experiments. Some experiments have been repeated at a flow rate of $10 \mu \mathrm{L} / \mathrm{min}$ to check the effect of possible rebinding. Rebinding and mass transfer limitation was also checked by the repetition of the experiments at lower levels of immobilized Hsp90. The identical results showed that these phenomena did not occur under the condition we used. Flow cells were occasionally regenerated with $10 \mu \mathrm{L}$ of 100 $\mathrm{mM} \mathrm{HCl}$ after peptide binding. This regeneration step allowed retention of over $95 \%$ of the original NPY binding capacity. To test the effect of geldanamycin, Hsp90 (140 $\mu \mathrm{g} / \mathrm{mL}$ ) was preincubated in HBS buffer with or without 18 $\mu \mathrm{M}$ geldanamycin (GIBCO) and $0.1 \%$ DMSO at room temperature for $30 \mathrm{~min}$ before assays.

Biotinylation of NPY13-36. NPY13-36 was biotinylated using the ECL protein biotinylation module (Amersham Pharmacia Biotech). The peptide was dissolved at $1 \mathrm{mg} / \mathrm{mL}$ in PBS containing 4\% biotinylation reagent. After $1 \mathrm{~h}$ incubation at room temperature, the mixture was applied to a Sephadex G-25 column equilibrated with PBS, and fractions containing the biotinylated peptide were collected.

Cross-Linking of Biotinylated NPY13-36 to Hsp90 and $\mathrm{CNBr}$ Cleavage. Hsp90 was mixed with or without biotinylated NPY13-36 at $20 \mathrm{mM}$ in $2 \mathrm{mM}$ potassium phosphate, $\mathrm{pH}$ 7.5. Cross-linking was started by addition of EDC (Pierce Chemical Co., Rockford, IL) at a final concentration of 2 $\mathrm{mM}$ and sulfo- $N$-hydroxysuccinimide (Pierce Chemical Co.) at $5 \mathrm{mM}$ and incubation for $30 \mathrm{~min}$ at $20^{\circ} \mathrm{C}$. The reaction was stopped by addition of glycine at the final concentration of $10 \mathrm{mM}$. The cross-linked product between Hsp90 and biotinylated NPY13-36 was cleaved with CNBr $(100 \mu \mathrm{g} /$ $\mu \mathrm{g}$ of protein) in $70 \%$ formic acid in the dark at room temperature overnight, and the reaction was stopped by 10fold dilution in distilled water. The sample was dried in an evaporator, solubilized in $20 \mathrm{mM}$ potassium phosphate, $\mathrm{pH}$ 7.5 , and resolved by SDS-PAGE using a $15-20 \%$ gradient gel. Resolved proteins were electrophoretically transferred to a PVDF membrane, which was either stained with amide black for amino acid analysis or incubated with 5\% skim milk in TBST $(150 \mathrm{mM} \mathrm{NaCl}, 20 \mathrm{mM}$ Tris- $\mathrm{HCl}$, and $0.05 \%$ Tween 20) for $3 \mathrm{~h}$ at room temperature for blotting. The membrane was incubated with $0.1 \%$ streptavidin-horseradish peroxidase conjugate (SA-HRP) in TBST for $1 \mathrm{~h}$ and washed with TBST three times for $10 \mathrm{~min}$, and biotinylated NPY13-36 was detected using the ECL system (Amersham Pharmacia Biotech). For Western blotting, the membrane was incubated with an anti-Hsp90 antibody, K41116A, followed by incubation with alkaline phosphatase-conjugated goat antimouse IgG (Bio-Rad) and detection by the BCIP/NBT phosphatase substrate system (Kirkegaard \& Perry Laboratories Inc., Gaithersburg, MD). Protein bands stained with amide black were excised from the membrane and subjected to amino acid sequencing at Iwaki Glass Co. Ltd. The first
10 amino acids from the $\mathrm{N}$-terminus were determined with each sample.

Circular Dichroism (CD) Measurement. The CD spectrum was measured using a Masco J-725 spectropolarimeter (Masco Co., Tokyo, Japan) at 25 or $50 \mu \mathrm{M}$ protein concentration in HBS buffer. The CD spectra of pure solvents were subtracted from those of peptide solutions to eliminate interference from cuvettes. The cell length was $0.02 \mathrm{dm}$, and the temperature was maintained at $20^{\circ} \mathrm{C}$ using a Masco PTC343 thermostat. The results were reported as mean residue ellipticities $[\theta]\left(\mathrm{deg} \mathrm{cm}^{2} \mathrm{dmol}^{-1}\right)$, and the helix content of each peptide was estimated using the secondary structure evaluation program (SSE-338W; Masco Co.), which transforms each spectrum by means of eigenvalue calculations to four orthogonal reference spectra (30).

Electron Microscopy. Purified brain Hsp90 $(20 \mu \mathrm{g} / \mathrm{mL})$ was mixed with biotinylated NPY13-36 $(0.5 \mu \mathrm{g} / \mathrm{mL})$ for $30 \mathrm{~min}$ at room temperature and then for another $30 \mathrm{~min}$ incubation with $8 \mu \mathrm{g} / \mathrm{mL}$ streptavidin in $20 \mathrm{mM}$ Tris- $\mathrm{HCl}$ and $150 \mathrm{mM} \mathrm{NaCl}, \mathrm{pH}$ 7.5. To make the Hsp90/antibody complex, Hsp90 was incubated with the K3720 antibody (16 $\mu \mathrm{g} / \mathrm{mL}$ ) in the same buffer. Samples were processed for electron microscopy as described (12). Briefly, the samples were mixed with the same volume of glycerol, sprayed onto a mica plate $(7 \times 7 \mathrm{~mm})$, placed on a rotary stage in a vacuum evaporator, and then shadowed with platinum at 4 ${ }^{\circ} \mathrm{C}$ and with carbon at $90{ }^{\circ} \mathrm{C}$. The replicas were examined with a JEM-1010 (JEOL DATUM) at $80 \mathrm{kV}$.

Expression of NPY in HeLa Cells. The NPY first-strand cDNA was synthesized from rat brain mRNA (Stratagene) using the Ready-to-Go You Prime first-strand beads (Amersham Pharmacia Biotech). Primers used for PCR reactions are as follows: NPY-IF ( $5^{\prime}$-aaaagaattccgeccgccatgatgctaggt-3') contains an EcoRI site, the upstream signal peptide for ER translocation, and the sequence of the first four amino acids of NPY. NPY-P (5'-aaaagaattctcagtaatcatcatcatcttgtagtcatatctctgtctggtgatga- $3^{\prime}$ ) contains the coding sequence of the last seven amino acids of mature NPY fused to the FLAG sequence, stop codon, and an EcoRI site. Amplified DNA was inserted into the EcoRI site of the vector pCAGGS, yielding pCAGGS/SP-NPY, where the complete NPY with the signal sequence was expressed under the control of the $\beta$-actin promoter. For transfection, $60 \%$ confluent HeLa cells were treated with lipofectamine plus (GIBCO-BRL) in Opti-MEM for $3 \mathrm{~h}$. After $21 \mathrm{~h}$ incubation in DMEM containing $10 \%$ fetal bovine serum, cells were transferred to the medium containing $0.5 \mu \mathrm{g} / \mathrm{mL}$ brefeldin $\mathrm{A}$ and incubated for an additional $3 \mathrm{~h}$. The cells were then washed twice with DMEM and lysed in TNE buffer $(10 \mathrm{mM}$ Tris-HCl, $\mathrm{pH} 7.8,1 \% \mathrm{NP} 40,0.15 \mathrm{M} \mathrm{NaCl}$, and $1 \mathrm{mM}$ EDTA containing $10 \mu \mathrm{g} / \mathrm{mL}$ aprotinin). Lysates were centrifuged at $14000 \mathrm{~g}$ for $20 \mathrm{~min}$, and the supernatants were immunoprecipitated with anti-Hsp90 (3G3) antibody, anti-Grp94 antibody, or a control antibody, FN-3E2. Immunoprecipitates were solubilized in Tris-glycine-SDS sample buffer and resolved by SDS-PAGE using 15-25\% gels (Daiichi Kagaku). Western blotting was performed using anti-Hsp90 (K41009) and biotinylated anti-mouse IgG or NPY antibody and biotinylated anti-rabbit Ig $(\mathrm{G}+\mathrm{L})$, and immune complexes were detected with the streptavidin-horseradish peroxidase conjugate (SA-HRP) and ECL system (Amersham). 
Table 1: Binding of Various Peptides to Immobilized Hsp90 ${ }^{a}$

\begin{tabular}{|c|c|c|c|c|c|}
\hline \multirow[b]{2}{*}{ peptide } & \multicolumn{4}{|c|}{ amino acids } & \multirow{2}{*}{$\begin{array}{c}R_{\mathrm{eq}}(\mathrm{RU}) / \\
(\mathrm{ng} \text { of } \mathrm{Hsp} 9 \\
\mathrm{mm}^{2} \text { ) }\end{array}$} \\
\hline & total & basic & acidic & hydrophobic & \\
\hline NPY13-36 & 24 & 5 & 2 & 9 & $1253 \pm 86$ \\
\hline MCD peptide & 22 & 9 & 0 & 6 & $202 \pm 24$ \\
\hline VIP & 28 & 6 & 2 & 10 & $98 \pm 6$ \\
\hline histatin 5 & 24 & 12 & 2 & 2 & $66 \pm 8$ \\
\hline dynorphin A & 13 & 5 & 0 & 5 & $43 \pm 5$ \\
\hline glucagon & 29 & 4 & 3 & 8 & $40 \pm 4$ \\
\hline$\left[\mathrm{Tyr}^{1}\right]$ somatostatin & 14 & 2 & 0 & 5 & $29 \pm 2$ \\
\hline PTH1-34 & 34 & 7 & 4 & 13 & $25 \pm 6$ \\
\hline
\end{tabular}

${ }^{a}$ Thirty-eight peptides were examined for binding to immobilized Hsp90 by SPR analysis as described in Materials and Methods. The eight peptides indicated in the table showed significant binding. Negligible binding was detected using the following 30 peptides: angiotensin I, angiotensin II, bradykinin, bradykinin potentiator B, bradykinin potentiator $\mathrm{C}$, calcitonin, kallidin, $\beta$-casmorphin-7, DSIP, $\alpha$-endorphin, guanylin, uroguanylin, insulin, laminin pentapeptide, magainin, $\alpha$-mating factor, neurokinin $\mathrm{A}$, neuromedin $\mathrm{B}$, neurotensin, nociceptin, oxytocin, chomogranin A, peptide T, platelet factor 4 , serum thymic factor, somatostatin, substance $\mathrm{P}$, substrate for tyrosine protein kinase, substrate for renin, and vasopressin. Data represent the mean \pm SD of three separate experiments.

\section{RESULTS}

Screening of Peptide Binding to Hsp90. Commercially available, biologically active peptides were screened for binding to Hsp90 using a surface plasmon resonance (SPR) biosensor with sensor chips containing immobilized Hsp90. In this method, a complex of Hsp90 and interacting peptides is detected by measuring the change in refractive index caused by the absorption of Hsp90 and binding peptides to the chip surface. SPR has been proven an efficient method for the characterization of the interaction of Hsp90 and other proteins and peptides $(26,29)$, so we chose this powerful technique for initial screening. Selected peptides varied in size from 5 (laminin pentapeptide) to 34 (PTH) amino acid residues and had different hydrophilic/hydrophobic properties. Our binding data showed that only 8 out of the 38 peptides bound to Hsp90 and that the carboxy-terminal fragment of neuropeptide Y (NPY13-36) exhibited an extremely intense binding in equilibrium $\left(R_{\text {eq }}\right)$ (Table 1 and Figure 1A). As a positive control, we examined the binding of a peptide corresponding to the heparin binding site of casein kinase II (CKII peptide), which is known to interact with Hsp90 (31). Specific binding was also seen with the CKII peptide, although $R_{\text {eq }}$ of the CKII peptide binding was six times lower than that of NPY13-36 (Figure 1A). Binding levels of NPY13-36 were proportional to the amount of immobilized porcine brain Hsp90, and a similar level of binding was observed with Hsp90 purified from L5178Y cells (data not shown), suggesting that the response is neither due to nonspecific binding to the sensor chip nor due to a tissue-derived contamination, such as the NPY receptor in the brain. To exclude the possibility of artificial binding of NPY13-36 to the chip, we immobilized NPY13-36-Cys and injected Hsp90 in solution. In this reverse experiment, Hsp90 bound to immobilized NPY13-36-Cys, confirming our previous data using NPY in solution and immobilized Hsp90 (Figure 1B).

Structural Importance of Peptide Binding to Hsp90. NPY has homologous amino acid sequences and a similar structure with the pancreatic polypeptide (PP) and peptide YY (PYY)
A

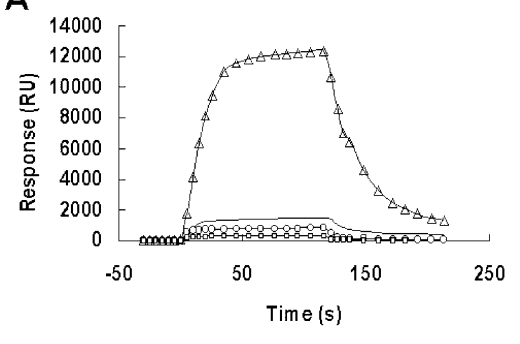

$\triangle$ NPY13-36 -a-VIP -a- glucagon - CKII peptide

B

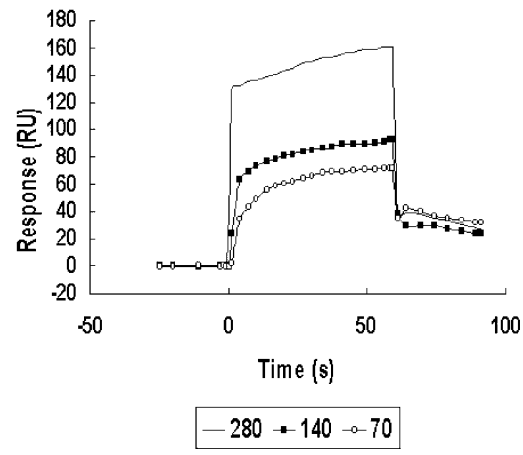

FIGURE 1: Neuropeptide Y (NPY) shows a particularly strong binding to Hsp90. Panel A: Binding of NPY13-36 and other peptides (CKII peptide, VIP, and glucagon) to immobilized Hsp90. Peptide $(50 \mu \mathrm{M} / \mathrm{mL})$ binding to Hsp90 was examined by surface plasmon resonance (SPR). The amount of immobilized Hsp90 was 8800 RU. Panel B: Hsp90 binding (70, 140, and $280 \mu \mathrm{g} / \mathrm{mL}$ Hsp90) to immobilized NPY13-36-Cys (830 RU). Sensorgrams were corrected to nonspecific binding to the reference sensor chips. Data are representatives of three independent experiments.

\begin{tabular}{lc}
\hline \multicolumn{1}{c}{ Table 2: pequence of NPY-Related Peptides ${ }^{a}$} \\
\hline NPY13-36 & \multicolumn{1}{c}{ amino acid sequence $^{\text {PAEDLARYYSALRHYINLITRQRY-NH }}{ }_{2}$} \\
PP13-36 & TPEQMAQYAAELRRYINMLTRPRY-NH \\
PYY13-36 & SPEELSRYYASLRHYLNLVTRQRY-NH \\
NPY13-36-RA & PAEDLAAYYSALAHYINLITAQRY-NH \\
\hline
\end{tabular}

${ }^{a}$ Arginine residues substituted to alanines are underlined.

$(32-34)$. To examine whether these related peptides also bind to Hsp90, we analyzed PP13-36 and PYY13-36, the homologous fragment peptides to NPY13-36 (Table 2). Figure 2A shows that PYY13-36 bound to Hsp90 approximately $75 \%$ as efficiently as NPY13-36, while PP1336 bound to Hsp90 to a lesser degree (the $R_{\text {eq }}$ value of PP1336 characteristic to the extent of its binding was approximately one-fifth that of NPY13-36). A sequence comparison of the three peptides showed that the arginine at the 19th amino acid is conserved in NPY and PYY but is replaced by glutamine in PP (Table 2). Structural studies by NMR and CD spectroscopy demonstrated that the C-terminal half of NPY forms a stable $\alpha$-helix (35) and residues $13-32$ of the NPY-related peptides form an amphiphilic $\alpha$-helix (33). We, therefore, substituted alanine residues for the original arginines at amino acids 19, 25, and 33 of NPY13-36 to remove all charged residues on the helix. The resulting peptide, NPY13-36-RA (Table 2), completely lost binding ability to immobilized Hsp90 (Figure 2B). To confirm this result, we examined the binding of Hsp90 to immobilized NPY1336-RA-Cys, a peptide with a cysteine residue at the carboxy terminus of NPY13-36-RA, on a sensor chip. While Hsp90 
A

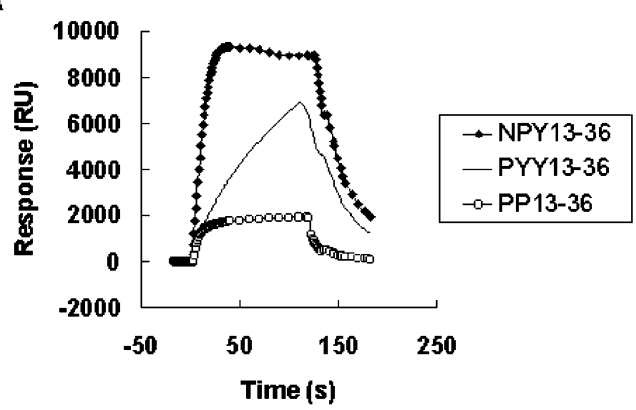

B

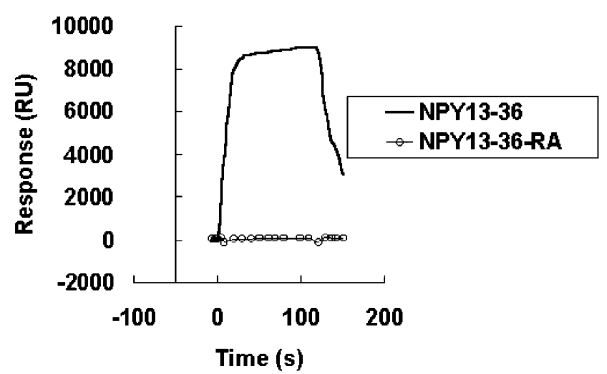

FIGURE 2: Structural characterization of NPY binding to Hsp90. Panel A: Binding of NPY and the pancreatic polypeptide family members, PYY and PP, binding to Hsp90. Binding of the peptides $(50 \mu \mathrm{M})$ to immobilized Hsp90 was examined by SPR. Panel B: Binding of NPY13-36 with arginine to alanine substitutions (NPY13-36-RA) and NPY13-36 to immobilized Hsp90. Sensorgrams were corrected to nonspecific binding to the reference sensor chips. Data are representatives of three independent experiments

Table 3: Helical Content of Peptides Determined in HBS Buffer ${ }^{a}$

\begin{tabular}{lcclcc}
\hline \multicolumn{1}{c}{ peptide } & $\begin{array}{c}\text { concn } \\
(\mu \mathrm{M})\end{array}$ & $\begin{array}{c}\text { helical } \\
\text { content }\end{array}$ & \multicolumn{1}{c}{ peptide } & $\begin{array}{c}\text { concn } \\
(\mu \mathrm{M})\end{array}$ & $\begin{array}{c}\text { helical } \\
\text { content } \\
(\%)\end{array}$ \\
\hline NPY13-36 & 50 & 90 & MCD peptide & 25 & 13 \\
NPY13-36 & 25 & 55 & VIP & 25 & 3 \\
PYY13-36 & 25 & 85 & histatin 5 & 25 & 31 \\
PP13-36 & 25 & 34 & dynorphin A & 25 & 11 \\
NPY13-36-RA & 50 & 56 & [Tyr ${ }^{1}$ ]somatostatin & 25 & 36 \\
CKII peptide & 25 & 0 & & & \\
\hline
\end{tabular}

${ }^{a}$ Peptides were dissolved in HBS buffer at the concentrations indicated and subjected to CD measurements with a spectropolarimeter as described in Materials and Methods. Data represent the mean of two separate experiments.

bound to NPY13-36-Cys (Figure 1B), it was hardly able to bind to immobilized NPY13-36-RA-Cys (data not shown). These results indicated that the three arginines are crucial for the binding of NPY13-36 to Hsp90.

To assess the contribution of the amphiphilic $\alpha$-helical structure to the binding to Hsp90, the secondary structure of the NPY-related peptides was determined by CD spectroscopy in the solvent used for the binding assay (Table 3). The CD spectra of the NPY-related peptides all showed characteristics of $\alpha$-helical structures. The $\alpha$-helical content of NPY13-36 was concentration dependent, suggesting that the $\alpha$-helical structure becomes stabilized at higher peptide concentrations. It is noteworthy that NPY13-36 and PYY1336 showed high $\alpha$-helical contents, whereas PP13-36 showed a lower content (34\%). On the other hand, regardless of complete disruption of binding to Hsp90, NPY13-36RA showed a $56 \%$ helical content at $50 \mu \mathrm{M}$, suggesting that the $\alpha$-helical content per se is not enough to induce binding to Hsp90. To estimate the structural significance and

\begin{tabular}{lc}
\hline Table 4: Inhibition of NPY Binding & \\
\hline \multicolumn{1}{c}{ peptide/protein } & $\begin{array}{c}\text { binding of } \\
\text { NPY } 13-36(\%)\end{array}$ \\
\hline$\alpha$-casein $(25 \mu \mathrm{M})$ & 17 \\
$\alpha$-casein $(2 \mu \mathrm{M})$ & 38 \\
$\alpha$-casein $(0.5 \mu \mathrm{M})$ & 75 \\
casein basic peptide $(100 \mu \mathrm{M})$ & 61 \\
casein acidic peptide $(100 \mu \mathrm{M})$ & 84 \\
histone H1 $(0.5 \mu \mathrm{M})$ & $100^{b}$ \\
CKII peptide $(50 \mu \mathrm{M})$ & 81
\end{tabular}

${ }^{a}$ Binding of NPY13-36 and various other peptides and proteins was measured by surface plasmon resonance as described in Materials and Methods and is shown as the ratio of real binding of peptides and proteins mixed with $25 \mu \mathrm{M}$ NPY13-36 compared with the theoretical binding calculated assuming purely additive effects. Data represent the mean of two separate experiments. ${ }^{b}$ With $5 \mu \mathrm{M}$ NPY13-36, 51\% binding occurred.

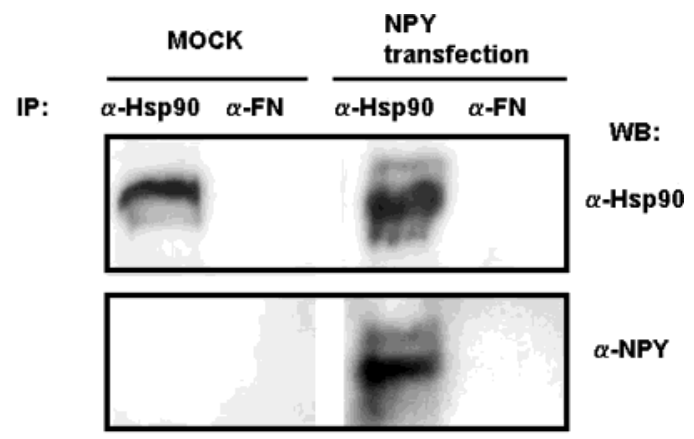

FIGURE 3: Coimmunoprecipitation of newly synthesized NPY with Hsp90. Lysates of NPY transfectant and control mock transfectant cells were subjected to immunoprecipitation with either an antiHsp90 monoclonal antibody, 3G3, or anti-cellular fibronectin. Immunoprecipitates were resolved by SDS-PAGE and blotted with anti-Hsp90 antibody (K41009) and an anti-NPY antibody. Data are representatives of three independent experiments.

specificity of NPY binding to Hsp90, a competition assay was performed using peptides and proteins known to interact with Hsp90 $(26,29)$. Binding of NPY13-36 was effectively inhibited by $\alpha$-casein, which possesses a partially denatured structure and inhibits chaperone activity of Hsp90 (5), and the effect was dose dependent (Table 4). We examined two peptides derived from $\alpha$-casein, a positively charged peptide (casein basic peptide) and a negatively charged peptide (casein acidic peptide). According to the sequence-based prediction of secondary structure (36), the casein basic peptide corresponds to a random secondary structure and the acidic peptide corresponds to a $\alpha$-helical domain of $\alpha$-casein. As shown in Table 4, the casein basic peptide partially inhibited NPY binding, whereas the acidic peptide did not. Histone H1 and CKII peptide showed only weak competition. These results gave further support to our conclusion that positively charged amino acids on NPY are important structural elements recognized by Hsp90.

Binding of Newly Synthesized NPY Precursor Proteins to Hsp90 in Cells. To examine if the interaction shown by the in vitro analysis reflects an in vivo interaction, we analyzed interactions of the newly synthesized NPY precursor with Hsp90 in the cytoplasm, since NPY is synthesized initially as a nascent precursor on cytosolic ribosomes. HeLa cells were transfected with either the vector only (Figure 3, mock) or the NPY expression vector (Figure 3, NPY transfection). Cells were treated with brefeldin A to accumulate the reactive NPY precursor in the ER before harvesting. As shown in 


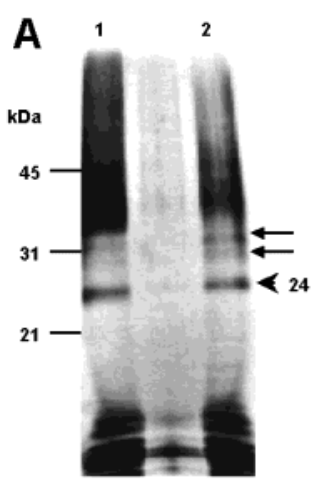

B

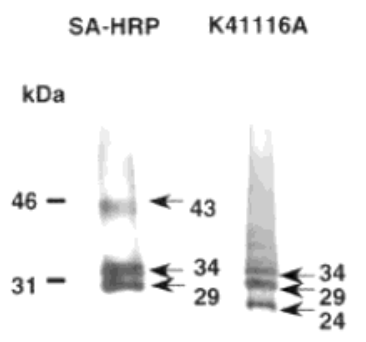

$20-$

C

\begin{tabular}{|l|c|}
\hline & Amino acid sequence \\
\hline $\begin{array}{l}\text { Porcine Hsp90a } \\
\text { The 29-kDa fragment }\end{array}$ & $\begin{array}{c}\text { (181) GRGTKVILHL } \\
\text { GRGTKVILXL }\end{array}$ \\
\hline
\end{tabular}

FIGURE 4: Detection of Hsp90 fragments cross-linked with biotinylated NPY13-36. Panel A: NPY-specific fragments of crosslinked NPY/Hs90 complexes. Hsp90 alone (lane 1) or a mixture of Hsp90 and biotinylated NPY (lane 2) was cross-linked with EDC followed by $\mathrm{CNBr}$ digestion. The arrowhead indicates the $24 \mathrm{kDa}$ major product from Hsp90 $\alpha$. The two arrows indicate those bands which could be detected only in cleaved products from a mixture of Hsp90 and NPY13-36. Panel B: Identification of Hsp90 and NPY as components of the cross-linked products. The CNBrdigested products of Hsp90 cross-linked with biotinylated NPY1336 were analyzed by blotting with streptavidin-horseradish peroxidase conjugates (SA-HRP) or anti-Hsp90 antibody (K41116A). Panel C: Comparison of amino acid sequences of porcine Hsp90 $\alpha$ and the $29 \mathrm{kDa}$ fragment. The $29 \mathrm{kDa}$ cross-linked product of porcine Hsp90 was subjected to amino acid sequence analysis after digestion with $\mathrm{CNBr}$. $\mathrm{X}$ indicates an unidentified amino acid.

Figure 3, the NPY precursor was copurified with Hsp90 only in the NPY transfected cells, whereas it was not associated with immunoprecipitates using anti-cellular fibronectin (Figure 3, $\alpha-\mathrm{FN}$ ) or anti-Grp94 antibodies (data not shown). These results suggest that the interaction of NPY and Hsp90 takes place in vivo.

Isolation of NPY Binding Fragments of Hsp90. To determine the NPY binding sites on Hsp90, we mixed biotinylated NPY13-36 and purified porcine brain Hsp90 and cross-linked them with EDC, a zero-length cross-linker. The cross-linked products were cleaved with $\mathrm{CNBr}$ and resolved by SDS-PAGE to see which fragment of Hsp90 is bound to biotinylated NPY13-36. As reported previously, cleavage of $\mathrm{Hsp} 90 \alpha$ with $\mathrm{CNBr}$ yields a number of peptides, among which a $24 \mathrm{kDa}$ fragment corresponding to the $181-$ 372 segment of Hsp90 is the longest (27) (Figure 4A, lane 2 , arrowhead). The unresolved bands of molecular masses larger than $40 \mathrm{kDa}$ observed by silver staining (Figure 4A) seem to represent incomplete cleavage products. When the cross-linked products of biotinylated NPY13-36 and Hsp90 were digested with $\mathrm{CNBr}, 29$ and $34 \mathrm{kDa}$ bands appeared in addition to a $24 \mathrm{kDa}$ band (Figure 4A, lane 2, arrows). When blotted with the streptavidin-horseradish peroxidase conjugate (SA-HRP) to identify which fragment includes biotinylated NPY, three bands of 29, 34, and $43 \mathrm{kDa}$ were detected (Figure 4B, left). To confirm that the 29 and 34 $\mathrm{kDa}$ fragments are indeed derived from the 181-372 segment of Hsp90, the filter was blotted with K41116A, which recognizes the epitope mapped between residues 216285 of Hsp90 (28). The antibody recognized the 29 and 34
$\alpha-H s p 90$ mAb

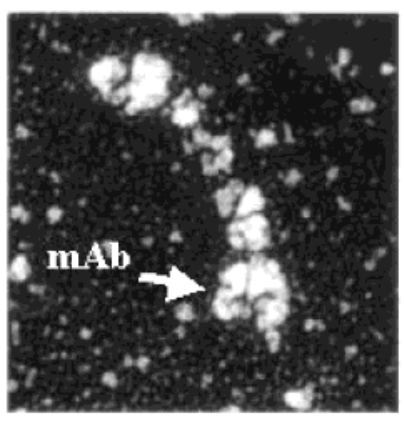

Biotin-NPY+SA

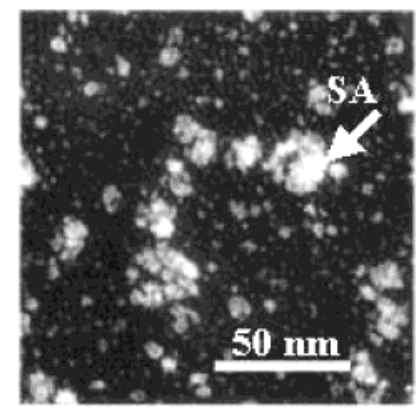

\section{Control}

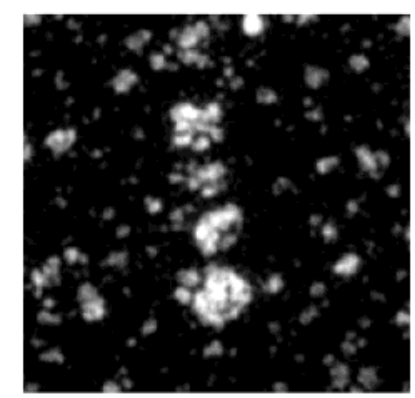

FIGURE 5: Electron microscopic images of Hsp90/NPY13-36 complexes. A mixture of Hsp90 and biotinylated NPY13-36 was incubated with streptavidin (SA) and was subjected to a regular specimen preparation protocol for electron microscopy (top right). As controls, an untreated Hsp90 preparation (bottom) as well as a preparation where Hsp90 was labeled with the anti-Hsp90 monoclonal antibody, K3720, recognizing amino acid residues 290312 of Hsp90 $\alpha$ (top left) was used. Arrows indicate K3720 (mAb) or streptavidin (SA) binding to Hsp90. Electron microscopic images are representatives of three separate experiments.

$\mathrm{kDa}$ as well as the $24 \mathrm{kDa}$ fragment (Figure 4B, right). This result suggests that the 29 and $34 \mathrm{kDa}$ bands are cross-linked products of the $24 \mathrm{kDa}$ fragment of Hsp90 and biotinylated NPY13-36. Furthermore, we performed amino acid sequence analysis with both the 24 and $29 \mathrm{kDa}$ bands and verified that these bands were composed of the Hsp90 $\alpha$ fragment starting at amino acid 181 (Figure 4C). These results clearly demonstrate that NPY13-36 binds to a region of Hsp90 $\alpha$ from amino acids 181 to 372 . Although the exact composition of the $34 \mathrm{kDa}$ fragment was not established, we speculate that, on the basis of the size, the 29 and 34 $\mathrm{kDa}$ fragments represent one $24 \mathrm{kDa}$ Hsp90 fragment crosslinked to one and two NPY molecules, respectively.

To examine the topology of the interaction of NPY1336 with Hsp90, we analyzed the interaction by a low-angle rotary shadowing replica image using electron microscopy (Figure 5). The Hsp90 dimer appears to consist of four tandemly aligned globules among which two end globules contain the N-terminal and the proximal domain (Figure 5, bottom). The monoclonal antibody K3720 bound to the end globules (Figure 5, top left), as it recognizes amino acids 290-312 of Hsp90 $\alpha$ (28). Since the K3720 epitope overlaps a possible NPY13-36 binding site (amino acids 181-372), we compared the view of the complex of Hsp90 $\alpha$ and biotinylated NPY 13-36 bound by streptavidin (Figure 5, top right) with that of K3720. Streptavidin bound to biotinylated NPY showed a comparable image to antibody K3720, indicating that the NPY binding site is mapped to the end globules of Hsp90. 


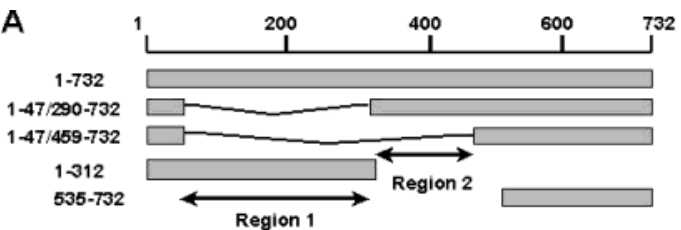

B

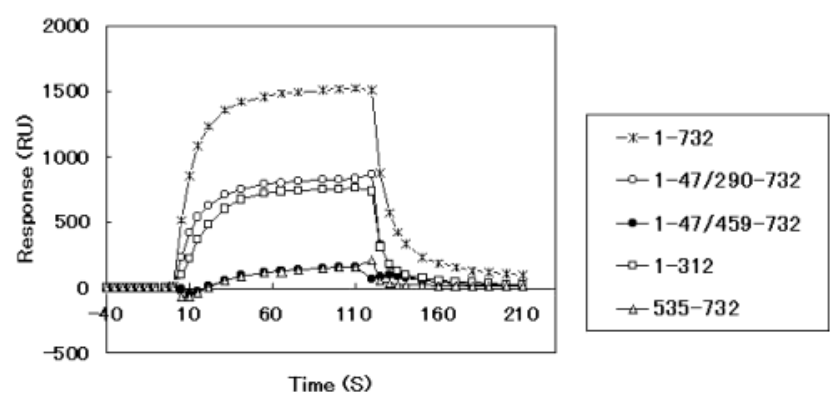

FIGURE 6: Binding of NPY13-36 to deletion mutants of Hsp90. Panel A: Hsp90 mutants with various deletions. Panel B: Sensorgrams of NPY13-36 binding to the deletion mutants. Recombinant proteins were purified from $E$. coli lysates and immobilized on surface plasmon resonance sensor chips at amounts proportional to their molecular mass (full length $1-732,85 \mathrm{~K}, 4100 \mathrm{RU} ; 1-47 /$ 290-732, 57K, $2800 \mathrm{RU} ; 1-47 / 459-732$, 42K, $2500 \mathrm{RU} ; 1-312$, 50K, $2700 \mathrm{RU}$; 535-732, 27K, $2100 \mathrm{RU}$. Data are representatives of three independent experiments.

To analyze the location of binding sites for NPY13-36 on Hsp90 further, deletion mutants of Hsp90 were fused to glutathione $S$-transferase (GST) (Figure 6A) and analyzed by SPR. Binding experiments revealed that some deletion mutants of Hsp90 showed lower binding ( $R_{\mathrm{eq}}$ values) for NPY13-36 compared to full-length Hsp90. Full-length Hsp90 showed a binding corresponding to approximately 1500 resonance units (RU), whereas the mutant 1-47/290732 and 1-312 showed half of this binding level (approximately $750 \mathrm{RU}$; Figure $6 \mathrm{~B}$ ). Almost all the rest of the binding was abrogated in the mutant 1-47/459-732. These lines of evidence suggest that there are at least two NPY1336 interaction sites on Hsp90: the first is located between the 47th and 290th residues (Figure 6A, region 1), and the other is located between the 312th and 459th residues (region 2). The NPY peptide showed far lower binding to the mutant $1-47 / 459-732$ and 535-732, showing that NPY13-36 does not bind to either the N-terminal 47 amino acids or the C-terminus of Hsp90.

\section{DISCUSSION}

We found that several commercially available and biologically active peptides bound to Hsp90 immobilized on a surface plasmon resonance sensor chip. Among those, the C-terminal peptide of NPY, NPY13-36, showed an intense binding with Hsp90. The unusualy high $R_{\text {eq }}$ value was probably linked to both the oligomerization of NPY13-36 under our assay conditions and the multiple binding sites of NPY13-36 on Hsp90. We had additional evidence for the high-affinity binding of NPY13-36 using the immobilized NPY13-36-Cys peptide and estimated the binding affinity of NPY13-36 comparable to that of CKII (26) (data not shown). NPY is a 36 amino acid peptide, and the C-terminal half folds into an amphiphilic $\alpha$-helix $(37,38)$. We measured the CD spectra of NPY13-36 and found a high $\alpha$-helical content (55\% at $25 \mu \mathrm{M}$ and $90 \%$ at $50 \mu \mathrm{M}$ ), suggesting that
NPY13-36 formed a stable amphiphilic $\alpha$-helix under our experimental conditions. This result is consistent with an NMR study demonstrating that the secondary structure of synthetic NPY13-36 is maintained as of the full-length NPY (39). Despite the high sequence homology of NPY with the pancreatic polypeptide family, PP13-36, a representative of the latter, bound only weakly to Hsp90. Although similar tertiary structures have been predicted for the two pancreatic polypeptides tested (PP13-36 and PYY13-36) and NPY (32, 33), the $\alpha$-helical content of PP13-36 under our experimental conditions was significantly lower than those of NPY13-36 and PYY13-36 as determined by CD spectrometry. This raised the possibility that high $\alpha$-helical content may contribute to peptide binding to Hsp90. On the other hand, among the peptides used in the SPR analysis, CKII peptide and VIP did not form an $\alpha$-helix under the experimental conditions used (Table 3 ) but showed a significant interaction with immobilized Hsp90. In addition, a mutant NPY13-36 with alanine substitutions showed abrogated binding capacity, although it retained a higher $\alpha$-helical content. These lines of evidence suggest that $\alpha$-helical content is not the exclusive factor to determine high-affinity peptide binding to Hsp90.

The peptide binding domains with different substrate specificities have been mapped on the $\mathrm{N}$-terminus and the C-terminus in Hsp90 $(7,8)$. In this study, we proposed another peptide binding domain (residues 181-372), which is not located in the N-terminal geldanamycin/ATP binding domain of Hsp90 (first to 210th residues). Consistent with our results, binding of NPY13-36 was insensitive to geldanamycin and was not augmented by ATP (IshiwatariHayasaka and Yahara, unpublished observation). Supporting the biochemical analysis, where the Hsp90 fragment between amino acids $181-372$ is cross-linked with NPY13-36, Hsp90 fragments containing amino acids 47-290 (Figure 6A, region 1) and amino acids $312-459$ (region 2) were shown to contribute to NPY binding in SPR analysis. Since all mutant Hsp90 fragments used in this assay are recognized in ELISA using an anti-Hsp90 antibody (28), they have proper structure unless irregular conformation takes place during the immobilization process. Region 1 contains the highly charged domain (amino acids 206-287), which is also referred to as the acidic region because in this region acidic amino acids are dominant. We confirmed that the full-length NPY binds to the polypeptide comprising amino acids 213-275 of chicken Hsp90 by SPR analysis (Soti and Csermely, unpublished observation). Since a mutant NPY13-36 with arginine to alanine substitutions (NPY13-36-RA) hardly interacted with Hsp90 and the binding was drastically disrupted in buffers with high ionic strength (data not shown), it seems that electrostatic interactions particularly contribute to the binding of NPY13-36 to Hsp90. As the highly charged domain overlaps the casein kinase II (CKII) binding site (26), we performed a competition assay to examine if the NPY binding site overlaps the CKII binding site. We found that the CKII peptide poorly inhibited NPY binding, whereas the casein basic peptide partially inhibited NPY binding (Table 4). From these lines of evidence, we speculate that basic amino acids of NPY play a significant role in the interactions with the acidic amino acids of Hsp90; however, the binding site is different from that of the CKII peptide. 
Hsp90 is known to preferably interact with polypeptides in the late folding stage where considerable secondary structure is present. Although there is a variety of substrate proteins reported, the structural features of substrates recognized by Hsp90 and the actual binding sites on Hsp90 have not been characterized. We propose that one of the primary structure preferences governing high-affinity binding to Hsp90 is positive charges aligned on a face of the $\alpha$-helix, and substrates having this structure may effectively bind to the region of amino acids 181-372 in Hsp90. Regarding the interaction between glucocorticoid receptor and Hsp90, it was shown that a predicted $\alpha$-helical region in the hormone binding domain is necessary for efficient Hsp90 binding (40). In addition, studies with antibodies against $\operatorname{Hsp} 90(41,42)$ and deletion mutants of Hsp90 suggest that a possible binding site for glucocorticoid receptor is encompassed by the NPY binding region $(25,43)$. Moreover, a binding site for serine/ threonine kinase $\mathrm{Akt} / \mathrm{PKB}$ was mapped in this region (amino acid residues 327-340 of Hsp90 $\beta$ ) (19). Thus, this structural basis might be involved in binding of some native substrates to Hsp90, although further experiments are required to confirm this possibility.

\section{ACKNOWLEDGMENT}

We thank Drs. Y. Miyata, Kyoto University, and Y. Minami, Oita Medical University, for L5178Y-derived Grp94 and Hsp90, respectively. We also thank Dr. Andy W. Kinley, University of Virginia, for help in editing the manuscript and Drs. H. Omote and J. Thomas Parsons, University of Virginia, for helpful discussion.

\section{REFERENCES}

1. Yahara, I., Minami, Y., and Miyata, Y. (1998) The 90-kDa stress protein, Hsp90, is a novel molecular chaperone, Ann. N.Y. Acad. Sci. 851, 54-60.

2. Csermely, P., Schnaider, T., Soti, C., Prohaszka, Z., and Nardai, G. (1998) The 90-kDa molecular chaperone family: structure, function, and clinical applications. A comprehensive review, Pharmacol. Ther. 79, 129-168.

3. Buchner, J. (1999) Hsp90 \& Co.-a holding for folding, Trends Biochem. Sci. 24, 136-141.

4. Wiech, H., Buchner, J., Zimmermann, R., and Jakob, U. (1992) Hsp90 chaperones protein folding in vitro, Nature 358, 169-170.

5. Yonehara, M., Minami, Y., Kawata, Y., Nagai, J., and Yahara, I. (1996) Heat-induced chaperone activity of HSP90, J. Biol. Chem. $271,2641-2645$.

6. Freeman, B. C., and Morimoto, R. I. (1996) The human cytosolic molecular chaperones hsp90, hsp70 (hsc70) and hdj-1 have distinct roles in recognition of a non-native protein and protein refolding, EMBO J. 15, 2969-2979.

7. Scheibel, T., Weikl, T., and Buchner, J. (1998) Two chaperone sites in Hsp90 differing in substrate specificity and ATP dependence, Proc. Natl. Acad. Sci. U.S.A. 95, 1495-1499.

8. Young, J. C., Schneider, C., and Hartl, F. U. (1997) In vitro evidence that hsp90 contains two independent chaperone sites, FEBS Lett. 418, 139-143.

9. Grenert, J. P., Sullivan, W. P., Fadden, P., Haystead, T. A., Clark, J., Mimnaugh, E., Krutzsch, H., Ochel, H. J., Schulte, T. W., Sausville, E., Neckers, L. M., and Toft, D. O. (1997) The aminoterminal domain of heat shock protein 90 (hsp90) that binds geldanamycin is an ATP/ADP switch domain that regulates hsp90 conformation, J. Biol. Chem. 272, 23843-23850.

10. Stebbins, C. E., Russo, A. A., Schneider, C., Rosen, N., Hartl, F. U., and Pavletich, N. P. (1997) Crystal structure of an Hsp90geldanamycin complex: targeting of a protein chaperone by an antitumor agent, Cell 89, 239-250.

11. Prodromou, C., Roe, S. M., O’Brien, R., Ladbury, J. E., Piper, P. W., and Pearl, L. H. (1997) Identification and structural charac- terization of the ATP/ADP-binding site in the Hsp90 molecular chaperone, Cell 90, 65-75.

12. Maruya, M., Sameshima, M., Nemoto, T., and Yahara, I. (1999) Monomer arrangement in HSP90 dimer as determined by decoration with $\mathrm{N}$ and $\mathrm{C}$-terminal region specific antibodies, J. Mol. Biol. 285, 903-907.

13. Meyer, P., Prodromou, C., Hu, B., Vaughan, C., Roe, S. M., Panaretou, B., Piper, P. W., and Pearl, L. H. (2003) Structural and functional analysis of the middle segment of hsp90. Implications for ATP hydrolysis and client protein and cochaperone interactions, Mol. Cell 11, 647-658.

14. Scheibel, T., Siegmund, H. I., Jaenicke, R., Ganz, P., Lilie, H., and Buchner, J. (1999) The charged region of Hsp90 modulates the function of the N-terminal domain, Proc. Natl. Acad. Sci. U.S.A. 96, 1297-1302.

15. Johnson, B. D., Chadli, A., Felts, S. J., Bouhouche, I., Catelli, M. G., and Toft, D. O. (2000) Hsp90 chaperone activity requires the full-length protein and interaction among its multiple domains, $J$. Biol. Chem. 275, 32499-32507.

16. Bardwell, J. C., and Craig, E. A. (1987) Eukaryotic Mr 83,000 heat shock protein has a homologue in Escherichia coli, Proc. Natl. Acad. Sci. U.S.A. 84, 5177-5181.

17. Louvion, J. F., Warth, R., and Picard, D. (1996) Two eukaryotespecific regions of Hsp82 are dispensable for its viability and signal transduction functions in yeast, Proc. Natl. Acad. Sci. U.S.A. 93, 13937-13942.

18. Lotz, G. P., Lin, H., Harst, A., and Obermann, W. M. (2003) Aha1 binds to the middle domain of Hsp90, contributes to client protein activation and stimulates the ATPase activity of the molecular chaperone, J. Biol. Chem. (in press).

19. Sato, S., Fujita, N., and Tsuruo, T. (2000) Modulation of Akt kinase activity by binding to Hsp90, Proc. Natl. Acad. Sci. U.S.A. 97, 10832-10837.

20. Minami, Y., Kimura, Y., Kawasaki, H., Suzuki, K., and Yahara, I. (1994) The carboxy-terminal region of mammalian HSP90 is required for its dimerization and function in vivo, Mol. Cell. Biol. $14,1459-1464$.

21. Nemoto, T., Ohara-Nemoto, Y., Ota, M., Takagi, T., and Yokoyama, K. (1995) Mechanism of dimer formation of the $90-\mathrm{kDa}$ heat-shock protein, Eur. J. Biochem. 233, 1-8.

22. Minami, M., Nakamura, M., Emori, Y., and Minami, Y. (2001) Both the N- and C-terminal chaperone sites of Hsp90 participate in protein refolding, Eur. J. Biochem. 268, 2520-2524.

23. Pratt, W. B., and Toft, D. O. (1997) Steroid receptor interactions with heat shock protein and immunophilin chaperones, Endocr. Rev. 18, 306-360.

24. Sullivan, W. P., and Toft, D. O. (1993) Mutational analysis of hsp90 binding to the progesterone receptor, J. Biol. Chem. 268 , 20373-20379.

25. Cadepond, F., Binart, N., Chambraud, B., Jibard, N., SchweizerGroyer, G., Segard-Maurel, I., and Baulieu, E. E. (1993) Interaction of glucocorticosteroid receptor and wild-type or mutated 90$\mathrm{kDa}$ heat shock protein coexpressed in baculovirus-infected Sf9 cells, Proc. Natl. Acad. Sci. U.S.A. 90, 10434-10438.

26. Miyata, Y., and Yahara, I. (1995) Interaction between casein kinase II and the 90-kDa stress protein, HSP90, Biochemistry 34, 81238129.

27. Minami, Y., Kawasaki, H., Suzuki, K., and Yahara, I. (1993) The calmodulin-binding domain of the mouse $90-\mathrm{kDa}$ heat shock protein, J. Biol. Chem. 268, 9604-9610.

28. Nemoto, T., Sato, N., Iwanari, H., Yamashita, H., and Takagi, T. (1997) Domain structures and immunogenic regions of the 90$\mathrm{kDa}$ heat-shock protein (HSP90). Probing with a library of antiHSP90 monoclonal antibodies and limited proteolysis, J. Biol. Chem. 272, 26179-26187.

29. Csermely, P., Miyata, Y., Soti, C., and Yahara, I. (1997) Binding affinity of proteins to hsp90 correlates with both hydrophobicity and positive charges. A surface plasmon resonance study, Life Sci. 61, 411-418.

30. Yang, J., Wu, C.-S. C., and Martinez, H. Z. (1986) Calculation of protein conformation from circular dichroism, Methods Enzymol. 130, 208-269.

31. Miyata, Y., and Yahara, I. (1992) The 90-kDa heat shock protein, HSP90, binds and protects casein kinase II from self-aggregation and enhances its kinase activity, J. Biol. Chem. 267, 7042-7047.

32. Glover, I. D., Barlow, D. J., Pitts, J. E., Wood, S. P., Tickle, I. J., Blundell, T. L., Tatemoto, K., Kimmel, J. R., Wollmer, A., and Strassburger, W. (1984) Conformational studies on the pancreatic polypeptide hormone family, Eur. J. Biochem. 142, 379-385. 
33. Allen, J., Novotny, J., Martin, J., and Heinrich, G. (1987) Molecular structure of mammalian neuropeptide Y: analysis by molecular cloning and computer-aided comparison with crystal structure of avian homologue, Proc. Natl. Acad. Sci. U.S.A. 84, 2532-2536.

34. Darbon, H., Bernassau, J. M., Deleuze, C., Chenu, J., Roussel, A., and Cambillau, C. (1992) Solution conformation of human neuropeptide $\mathrm{Y}$ by ${ }^{1} \mathrm{H}$ nuclear magnetic resonance and restrained molecular dynamics, Eur. J. Biochem. 209, 765-771.

35. Labelle, M., St.-Pierre, S., Savard, R., and Boulanger, Y. (1997) Solution structure of neuropeptide tyrosine $13-36$, a Y2 receptor agonist, as determined by NMR, Eur. J. Biochem. 246, 780-785.

36. Kumosinski, T. F., Brown, E. M., and Farrell, H. M., Jr. (1991) Three-dimensional molecular modeling of bovine caseins: alpha s1-casein, J. Dairy Sci. 74, 2889-2895.

37. Monks, S. A., Karagianis, G., Howlett, G. J., and Norton, R. S. (1996) Solution structure of human neuropeptide Y, J. Biomol. NMR 8, 379-390.

38. Cowley, D. J., Hoflack, J. M., Pelton, J. T., and Saudek, V. (1992) Structure of neuropeptide Y dimer in solution, Eur. J. Biochem. 205, 1099-1106.

39. Gurrath, M., Bisello, A., Bottazzo, K., Chung, C. W., Mammi, S., and Peggion, E. (1996) Conformational analysis of neuropep- tide Y segments by CD, NMR spectroscopy and restrained molecular dynamics, J. Pept. Sci. 2, 176-193.

40. Xu, M., Dittmar, K. D., Giannoukos, G., Pratt, W. B., and Simons, S. S., Jr. (1998) Binding of hsp90 to the glucocorticoid receptor requires a specific 7 -amino acid sequence at the amino terminus of the hormone-binding domain, J. Biol. Chem. 273, 13918-13924.

41. Tbarka, N., Richard-Mereau, C., Formstecher, P., and Dautrevaux, M. (1993) Biochemical and immunological evidence that an acidic domain of hsp 90 is involved in the stabilization of untransformed glucocorticoid receptor complexes, FEBS Lett. 322, 125-128.

42. Kang, K. I., Devin, J., Cadepond, F., Jibard, N., Guiochon-Mantel, A., Baulieu, E. E., and Catelli, M. G. (1994) In vivo functional protein-protein interaction: nuclear targeted hsp90 shifts cytoplasmic steroid receptor mutants into the nucleus, Proc. Natl. Acad. Sci. U.S.A. 91, 340-344.

43. Jibard, N., Meng, X., Leclerc, P., Rajkowski, K., Fortin, D., Schweizer-Groyer, G., Catelli, M. G., Baulieu, E. E., and Cadepond, F. (1999) Delimitation of two regions in the 90-kDa heat shock protein (Hsp90) able to interact with the glucocorticosteroid receptor (GR), Exp. Cell. Res. 247, 461-474.

BI034694A 